\title{
Outcome science in practice: an overview and initial experience at the Vanderbilt Spine Center
}

\author{
Matthew J. McGirt, M.D., ${ }^{1}$ Theodore Speroff, Ph.D., ${ }^{2-4}$ Saniya Siraj Godil, M.D., ${ }^{1}$ \\ Joseph S. Cheng, M.D., M.S., ${ }^{1}$ Nathan R. Selden, M.D., Ph.D., ${ }^{5}$ \\ And Anthony L. Asher, M.D.6 \\ ${ }^{1}$ Department of Neurosurgery, Vanderbilt University Medical Center; ${ }^{2}$ Vanderbilt Institute for Medicine and \\ Public Health, and Department of Medicine, Vanderbilt University School of Medicine; ${ }^{3}$ Center for Health \\ Services Research, and Geriatric Research Education and Clinical Center, Veterans Affairs, Tennessee Valley \\ Healthcare System; ${ }^{4}$ Department of Biostatistics, Vanderbilt University, Nashville, Tennessee; ${ }^{5}$ Department of \\ Neurological Surgery, Oregon Health \& Science University, Portland, Oregon; and ${ }^{6}$ Carolina Neurosurgery \\ and Spine Associates, Charlotte, North Carolina
}

\begin{abstract}
In terms of policy, research, quality improvement, and practice-based learning, there are essential principlesnamely, quality, effectiveness, and value of care - needed to navigate changes in the current and future US health care environment. Patient-centered outcome measurement lies at the core of all 3 principles. Multiple measures of diseasespecific disability, generic health-related quality of life, and preference-based health state have been introduced to quantify disease impact and define effectiveness of care. This paper reviews the basic principles of patient outcome measurement and commonly used outcome instruments. The authors provide examples of how utilization of outcome measurement tools in everyday neurosurgical practice can facilitate practice-based learning, quality improvement, and real-world comparative effectiveness research, as well as promote the value of neurosurgical care. (http://thejns.org/doi/abs/10.3171/2012.10.FOCUS12298)
\end{abstract}

KEY WORDS • outcomes • value • registry

$\mathrm{D}$ EFINING real-world effectiveness of care is central to evidence-based health care reform, comparative effectiveness research, and the health care value proposition. To promote sustainability in health care, providers and surgical treatments of the highest quality, effectiveness, and value will likely be preferentially purchased and sustained. Whether in policy, research, quality improvement, or practice-based learning, quality, effectiveness, and value are principles that are essential for all neurosurgeons to engage in to navigate the current and future US health care environment. The

\footnotetext{
Abbreviations used in this paper: $\mathrm{CPT}=$ Current Procedural Terminology; DRG = diagnosis-related group; DUKE = Duke Health Profile; EMR = electronic medical record; IOM = Institute of Medicine; $\mathrm{MCS}=$ mental component summary; NDI = Neck Disability Index; NHP = Nottingham Health Profile; NRS = numeric rating scale; ODI = Oswestry Disability Index $;$ PCS = physical component summary; PRO = patient-reported outcome; QALY = qualityadjusted life-year; $\mathrm{QOL}=$ quality of life; $\mathrm{RMDI}=$ Roland Morris Disability Index; SF-12 = 12-Item Short-Form Health Survey; SF-36 = 36-Item Short-Form Health Survey; VAS = visual analog scale; VSC = Vanderbilt Spine Center.
}

IOM defines health care quality as "The degree to which healthcare services for individuals and populations increase the likelihood of desired health outcomes." ${ }^{29}$ According to the IOM, quality care is safe, timely, efficient, patient centered, equitable, and effective. In the health care value equation (benefit/cost), effectiveness of care is the numerator and health care costs are the denominator. Without evidence of effectiveness, health care reform may reward cheaper care (cost-based purchasing) rather than more valuable care (value-based purchasing). Central to both quality and value of neurosurgical care is effectiveness of care.

Well-designed research trials may demonstrate treatment efficacy in artificially constrained research settings (such as that of a prospective, controlled, randomized trial). By contrast, the effectiveness of care is a result of applying an efficacious treatment in the real-world setting to the appropriate disease process, in the appropriate patient, at the appropriate time, in a safe manner, with the appropriate technical and health service delivery mechanisms. The IOM, AHRQ (Agency for Healthcare 
Research and Quality), and the Patient Protection and Affordable Care Act seek to promote measurement of real-world effectiveness as the principal goal of evidencebased health care reform. Patient-centered measurements of effectiveness should serve as the primary end points in comparative effectiveness research and be the basis for continued practice-based learning and quality improvement. Accurately defining effectiveness depends on the use of appropriate outcome measurement tools. The focus of this paper is to review the basic concepts of outcome measurement and demonstrate how outcome instruments can be used in practice for practice-based learning, quality improvement, and comparative effectiveness, and to promote the value of neurosurgical care.

\section{Choosing an Appropriate Outcome Measure}

In the current health care evidence paradigm, neurosurgeons must define effectiveness via outcome metrics that all health care stakeholders deem relevant. No longer will evidence of technical feasibility, radiographic metrics, fusion rates, widgetry, or safety alone be adequate to prove a treatment valuable. Rather than merely presenting the provider's perspective, outcome measurement must convey the impact on the patient's health status. It should measure aspects of health and general well-being that are meaningful to the patient and, ideally, should incorporate multiple domains of the patient's general health status, disease-specific health, and societal productivity. To this end, a multitude of PRO measures have emerged, with the aim of increasing patient involvement and point of view in health care.

Patient-reported outcomes are multidimensional constructs that measure the patients' perspective of their symptoms, physical function, general health, and QOL. ${ }^{1}$ Over the last few decades, a number of PROs have been developed and validated to measure outcomes for general health-related QOL and disease-specific disability. While investigators should preferentially use outcome instruments that have been validated as appropriate measurement tools in their targeted disease state, it is important to note that not all disease states have outcome instruments validated for measurement. While these additional tools develop and emerge in those disease states, generic health-related QOL measures can serve as accurate measures of effectiveness.

As several PROs have been introduced over time, it is important that careful selection is made to use appropriate instruments for a specific disease. There are several concepts to determine how good an instrument is for a particular condition, including reliability, validity, responsiveness, acceptability, feasibility, and ceiling and floor effects (Table 1). ${ }^{30}$ The following principles and examples highlight these concepts.

Reliability of an instrument represents the consistency in producing reproducible results. Variation is measurement error; the less the error, the more reliable the instrument. There are several ways to measure the reliability of an instrument, including internal consistency (Chronbach alpha), test-retest reliability (Pearson correlation coefficient), and interrater agreement (kappa coefficient and Bland-Altman plot). Example: If an out- come questionnaire is applied to a patient with a given extent of disease and disability but the answers and scores change each time the assessment is administered despite no change in disease or disability, it is not a reliable or accurate measure of the patient's state.

Validity is the extent to which an instrument accurately measures what it is supposed to measure. Content and face validity assess the domain of interest as to whether the questionnaire is appropriate to apply to a particular disease process. Criterion validity refers to how closely an instrument corresponds to the gold standard for measuring outcomes for a specific disease. Example: If an outcome instrument questions 3 domains (ability to ambulate, extent of leg pain, and sexual function), it will not be a valid measurement tool for disability in patients with dental abscess. It does not measure what it intends to measure, that is, dysfunction from oropharyngeal symptoms.

Responsiveness is the sensitivity of an instrument to detect small but clinically important changes. Responsiveness of an instrument to measuring meaningful change is a matter of comparing the change in scores with clinically meaningful changes in outcomes using multiple techniques, such as Cohen's effect size (standardized effect size), standard error of measurement, Guyatt coefficient, and the area under receiver operating characteristic curves. Example: If Validated Instrument 1 demonstrates a $10 \%$ change in score after treatment while Validated Instrument 2 demonstrates a $30 \%$ change in score in the same patient or population, Validated Instrument 2 is more responsive. This can occur when a 5-domain instrument targets additional domains of function that improve compared with a similar 3-domain instrument. This can also occur if only 2 of 5 of the domains targeted by one instrument are affected by treatment when 4 of 5 of the domains targeted by another instrument are affected by treatment.

Acceptability refers to how acceptable a particular instrument is to patients (or respondents). This is determined by mode of administration, administration time, response rate, and percentage of missing data. Acceptability is also dependent on what is asked and how, as well as the difficulty of language and comprehension. Example: If all 5 questions on an outcome instrument focus on sexual function, and the culture of the patient population dictates that patients are uncomfortable disclosing personal details of sexual capacity, low compliance with the instrument may preclude its use.

Feasibility refers to the ease of administration and processing of the questionnaire (response burden). Selfadministered and shorter questionnaires are more feasible than interviewer-administered and longer questionnaires. Also, sampling, distributing to respondents, and cost and resources of outcome instruments affect feasibility. Example: If an outcome questionnaire requires more time, energy, or investment than is feasible for the patient population with the targeted disease, there will be minimal compliance with assessment.

\section{Ceiling and Floor Effects}

High ceiling and floor effects highlight the inability of a questionnaire to discriminate severely disabled and mildly disabled patients, respectively. This is the scope of 
Outcome measurement in neurosurgery practice

TABLE 1: Measurement criteria for the US Veterans Associations' Compensation and Pension Examination Program (CPEP) quality indicators that have become accepted standards for quality and outcomes measurements in health care

\begin{tabular}{|c|c|}
\hline Criterion & Definition \\
\hline important & $\begin{array}{l}\text { Stakeholders must generally agree that the measure is important. Quality measures should be strategically important \& link to } \\
\text { an organization's aims and action plans. }\end{array}$ \\
\hline logical & The measure must make sense to stakeholders \& process owners; it should be easily understood. \\
\hline process \& outcomes & $\begin{array}{l}\text { Measures for quality improvement should link to the key features of what is done (process) to bring about impact on the key out- } \\
\text { comes; that is, improvements in process bring about change in outcomes \& thus improve quality. }\end{array}$ \\
\hline useful & A quality measure must permit data-driven action. Measures that cannot be acted on should not be collected. \\
\hline common & $\begin{array}{l}\text { Pragmatic indicators stem from common events and processes. Situations that apply rarely (e.g., estimated }<5 \% \text { ) or where per- } \\
\text { formance is already high (e.g., estimated }>95 \%) \text { would not provide the statistical variation needed for a useful indicator. }\end{array}$ \\
\hline relevant & The relevance \& justification for the indicator must be clearly referenced by evidence or literature. \\
\hline feasible & $\begin{array}{l}\text { It must be possible to implement, collect, \& display the measure w/in acceptable time frames, level of effort, \& resource utiliza- } \\
\text { tion. }\end{array}$ \\
\hline valid & $\begin{array}{l}\text { Measures must meet the criteria for good science: precise \& reproducible (reliable), accurate \& meaningful (valid), \& sensitive to } \\
\text { detect changes across time. }\end{array}$ \\
\hline objective & An indicator must have clear, practical instructions for implementation to improve its reliability \& validity. \\
\hline current & The measure must be capable of providing timely, \& not delayed, feedback. \\
\hline side effects & $\begin{array}{l}\text { In many cases, it is preferred that indicators have no side effects that could bring about a negative impact on the work process } \\
\text { (e.g., delay or unduly increase costs). }\end{array}$ \\
\hline
\end{tabular}

the continuum of measurement. Ceiling effect means that the scores are extremely skewed on the high end; thus, there is no differentiation of these respondents and for improvement in group change (that is, inability to measure change because of a shortcoming of the scale). The inverse is true for floor effect. Activities of daily living scales work well with severely disabled but not the nor$\mathrm{mal} /$ nondisabled population, for which instrumental activities of daily living scales are more responsive. Satisfaction scales are notorious for ceiling effects. Example: If an NRS for pain (range 0-10) is known to have a ceiling effect, then it will be poorly able to differentiate treatment effectiveness within the range of severe pain.

Neurosurgeons treat a wide variety of diseases. Hence, reliance on a wide variety of disease-specific and general outcome instruments may be necessary to quantify the effectiveness of the spectrum of treatments neurosurgeons offer. While the ideal measures of outcome will vary among cerebrovascular disease, neurooncology, and spinal disease-and the symptoms and treatment goals that are meaningful to patients will differ widely for these disease states-we review basic concepts of generic QOL and disease-specific disability measures below in the context of a single disease state: spine pathology.

\section{Generic and Disease-Specific Outcome Measures in Spinal Conditions}

A disease state affects several aspects of a patient's life. If we take the example of degenerative spine disease and low-back pain, it not only leads to pain and disability, but it also affects general health and QOL of the patient and leads to financial loss associated with work disability. ${ }^{8}$ The aim of comprehensive spine care is to improve not only the patient's pain, but also to lead to improve- ment in physical function, QOL, and overall health state and to optimize occupational capacity and societal contribution. Thus, comprehensive assessment of spine outcome includes generic measures of 1) health-related QOL (SF-36 and SF-12), 2) preference-based health state (the Euro-Qol EQ-5D and SF-6D), and 3) occupational capacity and return to work, as well as disease-specific measures that assess 1) pain (VAS and NRS) and 2) functional disability (ODI, NDI, and RMDI). For each measure, these instruments have been validated in the setting of self-administration, with the exception of the Short-Form Health Survey scales, which have been widely used in telephone interviews. Generic outcome measures provide a common metric of functional status that allows for comparison across multiple disease states and domains. Disease-specific measures are more focused and relevant to a particular disease state and therefore are more responsive to disease-specific treatment and functioning than generic instruments. For these reasons, most research studies or registry efforts use both generic and disease-specific measures.

\section{Generic Outcome Measures}

Generic outcome instruments are designed for broad assessment of general health and QOL. They may be less responsive than disease-specific measures as they do not cover all domains specific to a particular disease, but they allow for comparison across various disease states and are also helpful when validated disease-specific measures for a particular condition are not available. ${ }^{30}$ Commonly used generic measures for patients with spine pathology include the SF-36, SIP (Sickness Impact Profile), ${ }^{6}$ NHP, ${ }^{24}$ DUKE, ${ }^{37}$ and COOP/WONCA charts. ${ }^{4}$ Although all of these measures have been used in patients with low-back pain, the SF-36 has several advantages over the others 
and has been the preferred instrument. ${ }^{30}$ The Sickness Impact Profile has been most extensively studied in the literature, but it has limited feasibility (136 items) compared with the SF-36 (36 items). The NHP is comparable to the SF-36 in terms of feasibility and ease of use, but it has high ceiling and floor effects and is less responsive to meaningful change. ${ }^{14,15,30,32}$ The DUKE has low test/ retest reliability compared with other measures, whereas COOP/WONCA charts have not been extensively studied in patients with spine pathology, and further validation studies are required to determine their usability. ${ }^{14,15,30,32}$ Hence, the generic health-related QOL measure SF-36 is described below as an example.

The SF-36 is a generic health measure used for various conditions, including spine pathology. ${ }^{5}$ It was published by Ware and Sherbourne in 1992, and later on, several validation studies were carried out. ${ }^{32,40,44}$ The SF-36 has been found to have high reliability and responsiveness for use in spine pathology. It is validated for selfadministration as well as interviewer administration. It is a 36-item questionnaire consisting of 8 domains (vitality, physical functioning, bodily pain, general health perception, physical role functioning, emotional role functioning, social role functioning, and mental health) and is most commonly summarized as 2 scores, the PCS and MCS scores. Ware and colleagues ${ }^{43}$ introduced a shorter 12-item version (SF-12) in 1996 and validated its use in long-term studies confirming increased feasibility of administration. The SF-12 has been used in a number of surgical and medical spine studies and takes an average of 5 minutes to administer. Items focus on how the disease impacts general health, activities of daily living, emotional well-being, and how physical pain or emotional distress affect social and occupational function. The PCS and MCS scores are calculated using the scores of 12 items and range from 0 to 100 , where 0 represents worst health and 100 represents best health.

\section{Disease-Specific Outcome Measures}

Disease-specific measures assess symptoms and loss of functionality caused by a specific disease process. Outcome measures specific for spine pathology assess back, leg, neck, or arm pain and how it leads to limitations in activities of daily living. Several disease-specific measures for spine pathology have been introduced and validated over time: ${ }^{25} \mathrm{ODI},{ }^{17} \mathrm{NDI},{ }^{42} \mathrm{RMDI},{ }^{38} \mathrm{LBOS}$ (Low Back Outcome Score), ${ }^{20}$ QBPDS (Quebec Back Pain Disability Scale), ${ }^{26,27}$ and WDI (Waddell Disability Index). ${ }^{42}$ The ODI and RMDI have been most widely used as disease-specific measures for back pain. They have been validated in several long-term studies and have been found to be reliable and responsive to meaningful change. ${ }^{25}$ In a recent systematic review, Chapman et al. ${ }^{12}$ analyzed randomized clinical trials utilizing outcome instruments for the measurement of treatment success for chronic lowback pain. They demonstrated ODI to be the most commonly used and responsive measure for assessing outcomes after treatment for chronic back pain.7,18,19,22,28,31,34${ }^{36}$ Although some studies have shown that the RMDI has better responsiveness than the ODI, the ODI has higher responsiveness than the RMDI for detecting change in more severely disabled patients with back pain, correlates well with the RMDI $(\rho=0.77)$, and is more feasible (10 items) than the RMDI (24 items). ${ }^{13}$ The Waddell Disability Index is an acceptable alternative, but it only measures physical function..$^{25}$ Most other measures have been found to be less responsive than the ODI and RMDI. Similarly, the NDI has been found to be the most responsive, valid, and reliable instrument for cervical spine pathology, and there is a paucity of literature on other disease-specific PROs for cervical disease. ${ }^{41}$

The ODI is often considered the principal tool for measuring severity of functional disability related to back pain. It was first published in 1980 with several new versions of the questionnaire following since then. ${ }^{17}$ The ODI has been validated in 14 different languages and moderately correlates with NRS/VAS pain scales $(r=0.62){ }^{12,21}$ The ODI may show greater responsiveness because it more broadly covers various aspects of functional status pertinent to spinal disorders and is not limited only to assessment of severity of pain. Validation studies have demonstrated excellent face and criterion validity for the ODI, which has itself has been used to validate other functional outcome measures, such as the Pain Disability Index, Low Back Outcome Score, and Aberdeen Score. ${ }^{17}$ The ODI is a 10-item questionnaire with 6 responses for each question. The first response for each question has a score of 0 and the sixth response has a score of 5. Thus, the maximum score for the ODI is 50, and it is usually reported as a percentage $(0 \%-100 \%)$. It assesses the intensity of low-back symptoms and the resulting limitations in daily activities (self-care, lifting, walking, sitting, standing, sleeping, and traveling), as well as sexual and social function. A score of $0 \%-20 \%$ indicates minimal disability, 20\%-40\% moderate disability, 40\%-60\% severe disability, 60\%-80\% crippling effects, and 80\%$100 \%$ completely disabled and bedbound. ${ }^{17}$

\section{Preference-Based Measures}

Preference-based health state measures, which have been primarily developed for economic evaluations, are being increasingly used in outcome studies. Such measures yield a metric, known as the utility score, that reflects a society's preferences for different health outcomes, or how a health state is valued by a specific societal perspective. ${ }^{33}$ The EuroQol EQ-5D, for example, generates 243 possible health states based on 3 possible answers for 5 domains. Several population-based valuation studies have been conducted in many countries to calculate a QALY value for each of the 243 health states. In the US, these values are measured on a scale of -0.11 to 1.0 , where -0.11 represents worst heath state possible (death) and 1.0 represents the best health state possible. The most commonly used valuation methods for determining how a population values a unique health state includes standard gamble and time tradeoff. The 3 commonly used standardized questionnaires to calculate health-state utility values are the Euro-Qol EQ-5D, ${ }^{16}$ SF-6D (derived from the SF-36), ${ }^{9}$ and the Health Utilities Index. These generic preference-based utility instruments are feasible to use compared with valuating utility values using the standard gamble or time tradeoff method. Although they are very 


\section{Outcome measurement in neurosurgery practice}

TABLE 2: Variables obtained via EMR or phone interview in the VSC registry*

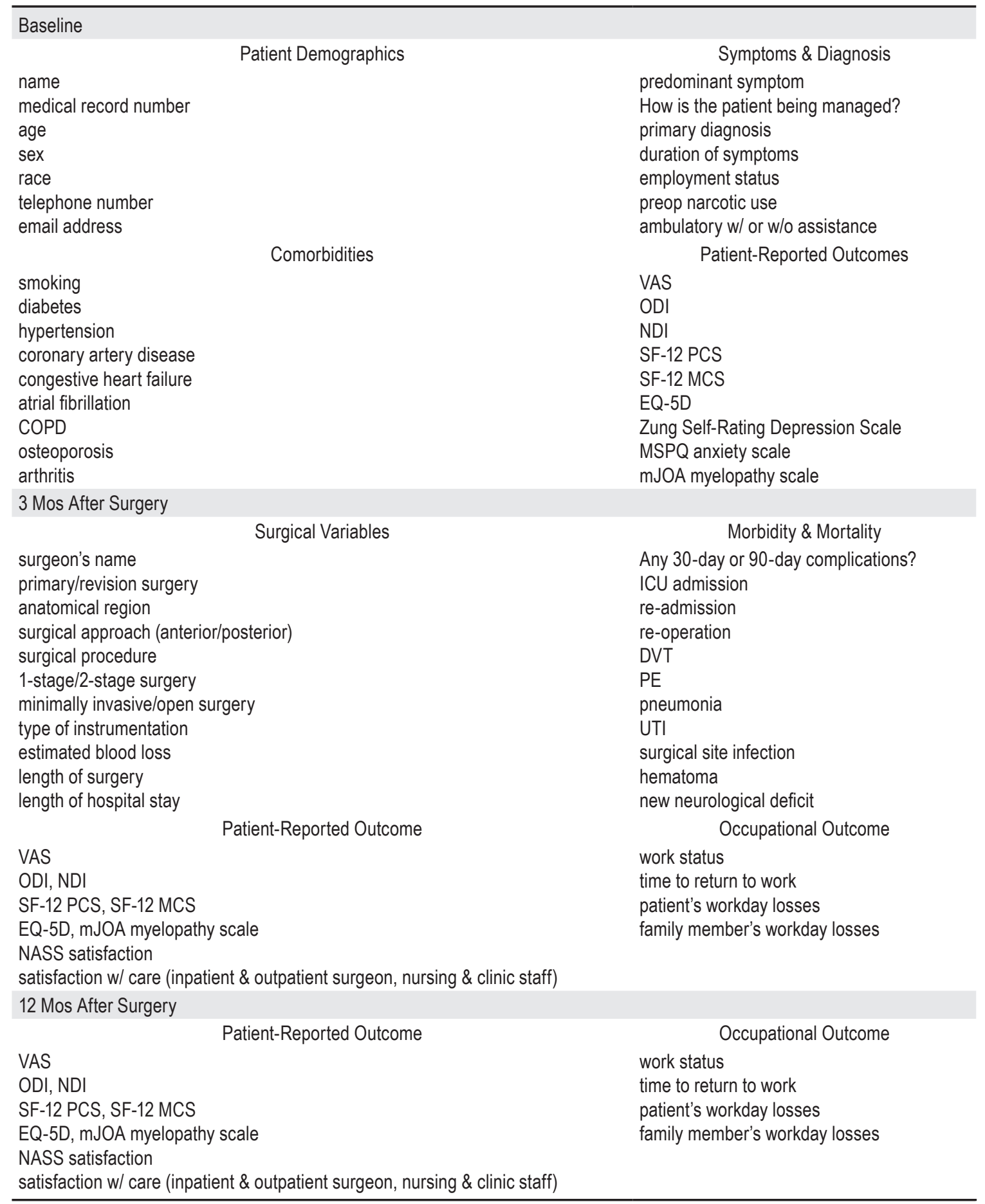

* $\mathrm{COPD}=$ chronic obstructive pulmonary disease; DVT = deep venous thrombosis; $\mathrm{mJOA}=$ modified Japanese Orthopaedic Association; MSPQ = Modified Somatic Perception Questionnaire; NASS = North American Spine Society PE = pulmonary embolism; UTI = urinary tract infection.

practical to use, they may lack sensitivity for some specific disease conditions and may have high ceiling (EQ-5D) and floor (SF-6D) effects. Data from preference-based measures are commonly used to calculate QALYs, which are commonly used for cost-utility analyses. For example, if the EQ-5D score of a patient with lumbar disc herniation improves from 0.46 preoperatively to 0.90 postoperatively and the patient experiences this health-state benefit 


\section{J. McGirt et al.}

over 10 years, the QALY gain of the patient is 4.4 QALYs $(0.44 \times 10)$.

The EQ-5D is the most commonly used preferencebased health instrument. It has good reliability and has been validated in 5 different languages. ${ }^{10,11}$ It has only been validated for self-administration and assesses 5 different domains (mobility, self-care, usual activities, pain/ discomfort, and anxiety/depression), with 3 different responses for each domain (no problem, some problem, and extreme problem). As previously described, an EQ-5D questionnaire generates one of 243 different result combinations, which is then coded and converted to an index score (QALY) by using published values determined by a US-specific valuation study. ${ }^{39}$ The US preference states have been calculated using the time tradeoff technique. This instrument allows a populations value of health states that can be compared across any disease state.

\section{Return to Work}

Recently, the literature has highlighted the importance of occupational capacity and return to work after spine treatment, which is now used more frequently given its relevance to multiple health care stakeholders. ${ }^{3}$ As a functional domain, return to work is often most meaningful to patients (because of financial well-being) and is also important from a societal and policy perspective (because of societal productivity). Measuring how a disease affects workdays missed and overall work capacity for those able to work is necessary to determine the financial impact and burden a disease state poses on the patient as well as on society. A standard tool for assessment of occupational capacity is not yet available for spine pathology. There is no universally accepted definition of functional capacity. Different occupations require different minimal functional capacity. These problems have limited the development of a standard tool. Nevertheless, outcome assessments in spine disease have increasingly begun reporting time to return to work as a measure of indirect cost and a rough estimate of gain of occupational functionality after treatment.

\section{Outcome Measurement in Practice: Initial Experience of the VSC}

The VSC is a multidisciplinary spine care center comprising providers from the Departments of Orthopedic Surgery, Neurosurgery, Physical Medicine \& Rehabilitation, Anesthesiology, Radiology, and Pain Management. Standardized outcome measurement has been used for all patients undergoing spine surgery performed by

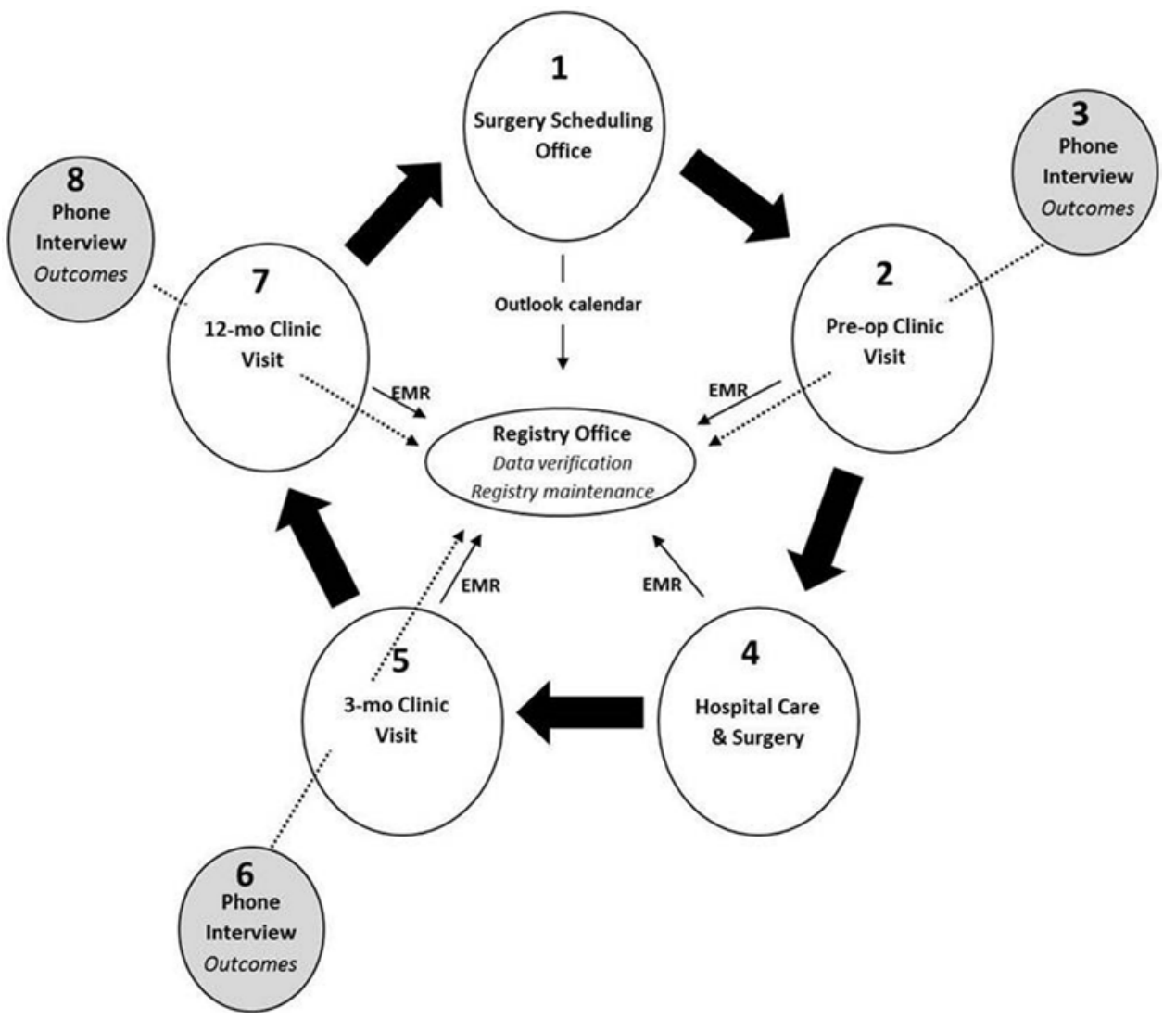

Fig. 1. Flowchart demonstrating the functioning of Vanderbilt Prospective Spine Registry. Spine surgeries scheduled at Vanderbilt Hospital are added to the Spine Registry Outlook calendar (1). Baseline demographics and patient-reported outcomes are collected during the preoperative clinic visit (2) and during the baseline phone interview conducted by registry associates (3). Surgical variables and perioperative morbidity data are obtained by reviewing the patient's EMR (4). Similarly, 3-month outcomes and resource utilization (5 and 6 ) and 12-month outcomes and resource utilization (7 and 8 ) are obtained during clinic visits and phone interviews. 
one of the 6 surgeons at the Vanderbilt University Medical Center for 3 consecutive years and is considered standard care for all surgical patients. The aim of utilizing validated outcome instruments in routine care and recording prospectively in a longitudinal registry was multifold: 1) to promote practice-based learning and quality improvement, 2) to demonstrate to outside health care stakeholders the safety and effectiveness of care delivered at Vanderbilt University Medical Center, and 3) to carry out comparative effectiveness research. What follows describes the initial VSC experience utilizing a real-world prospective registry with validated outcome instruments in standard spine care.

\section{Patient Enrollment and Outcome Measurement}

All patients undergoing spine surgery at the VSC are included in a prospective longitudinal spine registry regardless of diagnosis or surgical treatment. What ultimately allows outcome collection for all surgical spine care delivered at the VSC is the lack of required written informed consent. The Vanderbilt University Institutional Review Board determined that the Spine Center Outcomes Registry did constitute a form of research since the aim was to perform comparative effectiveness research. Hence, it would require annual institutional review board re-review and oversight. However, because the 1-year outcome assessment was administered to all patients without alteration to standard care or treatments delivered, the institutional review board believed participation to be of minimal risk to patients, and a waiver of written consent was granted.

At the time of surgical decision making and informed written consent, all patients are informed that they will be given outcome questionnaires in clinic or be called on the phone to respond to outcome questionnaires as a part of their standard care. Once patients have committed to surgery, the case details and date are posted on a Microsoft Outlook calendar for the individual surgeon. Unless the patient refused participation in the registry, the scheduled case is also posted on the centralized Microsoft Outlook calendar of the registry. Three registry associates then populate the preoperative, 3-month, and 12-month time points in the Web-based REDCap (Research Electronic Data Capture) registry portal to generate automated email notifications on those dates. All data are collected and managed using REDCap tools hosted at Vanderbilt University. ${ }^{23}$

These 3 registry associates also coordinate all data collection via EMR review and patient phone interview. Variables prospectively obtained from EMRs and phone interviews are listed in Table 2. Variables are included as standard in clinic documentation templates. When outcome measures are not recorded in the EMR during the preoperative, 3-month, or 12-month clinic visit, one of the 3 registry associates will contact the patient by phone to administer the questionnaires and enter the answers into the Web-based REDCap portal (Fig. 1). The 3 registry associates are funded by the hospital's quality improvement office. Questionnaires administered include measures of the following: 1) pain (NRS for back, neck, arm, and leg pain [range 0-10]), 2) disease-specific physical disability (ODI or NDI [range 0\%-100\%]), 3) mood disability (Zung
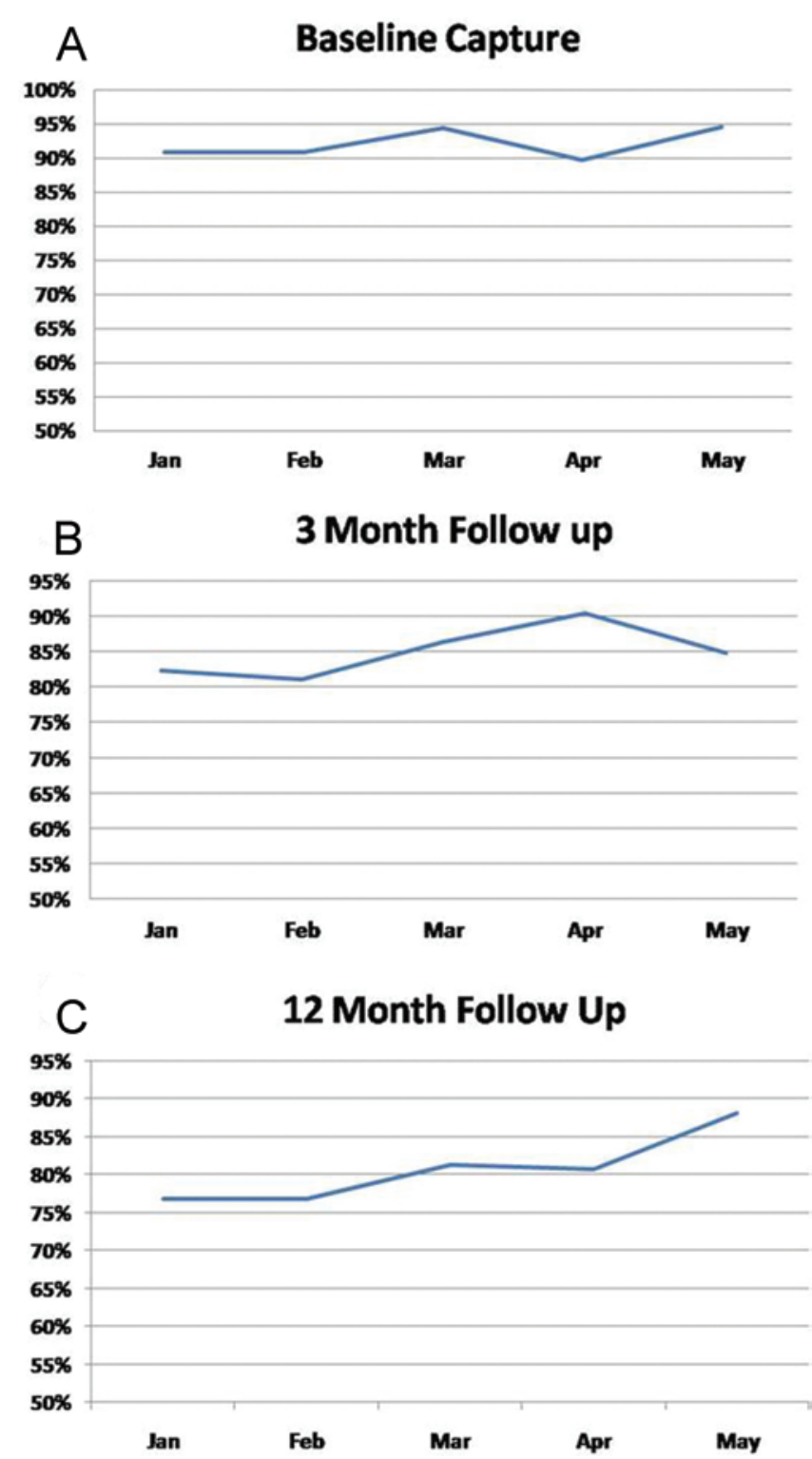

FIG. 2. Graphs showing the automated analysis of patient capture rate at baseline (A), 3 months postoperatively (B), and 12 months postoperatively (C). At baseline, 92\% of patients undergoing elective spine surgery at the VSC agreed to participate in baseline outcome questionnaires. On average, more than $80 \%$ of patients complete outcome questionnaires 3 and 12 months after spine surgery. Baseline patient enrollment and follow-up rates vary month to month. Real-time analysis of data capture allows for methods refinement if patient follow-up drops.

Depression index [range 25-100]), 4) generic health-related physical and mental QOL (SF-12 PCS [range 0-100] and MCS [range 0-100]), and 5) preference-based health status (EQ-5D [QALY range -0.11 to 1.0]). The feasibility of this process was enhanced by standardizing clinical and operative note dictation and centralizing all registry data entry to a single computer and phone station (Fig. 1). For each patient, all medical chart data are accessed from a Web-based EMR and entered into a Web-based registry data entry portal (REDCap) on the same computer screen all while the patient is on the phone with the registry associate via Bluetooth earpiece. 


\section{A VAS- Back Pain/Neck Pain}

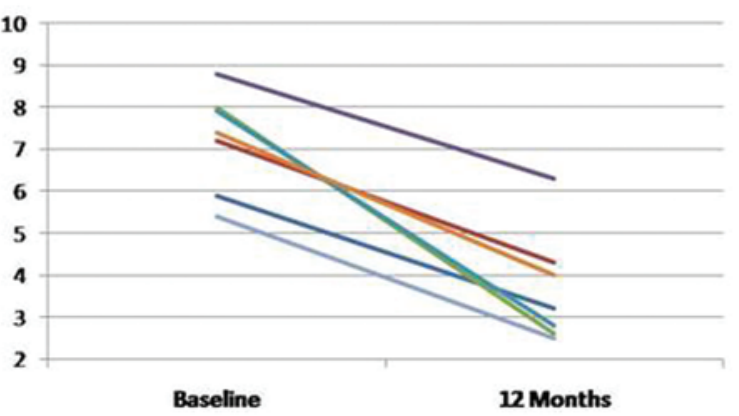

SF-12

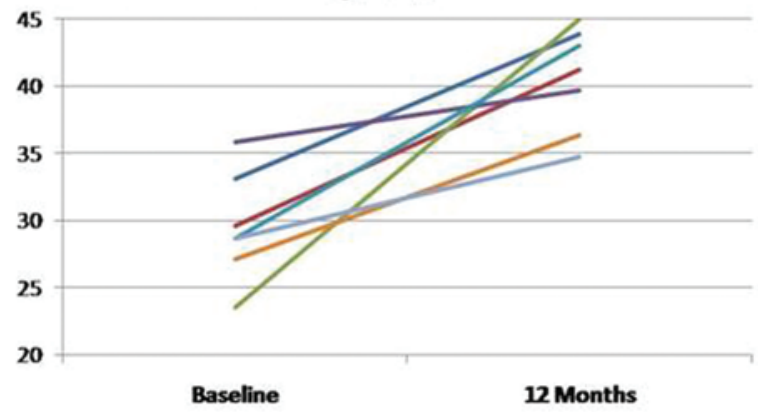

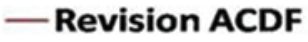

ACDF

- Lumbar Laminectomy - Deformity

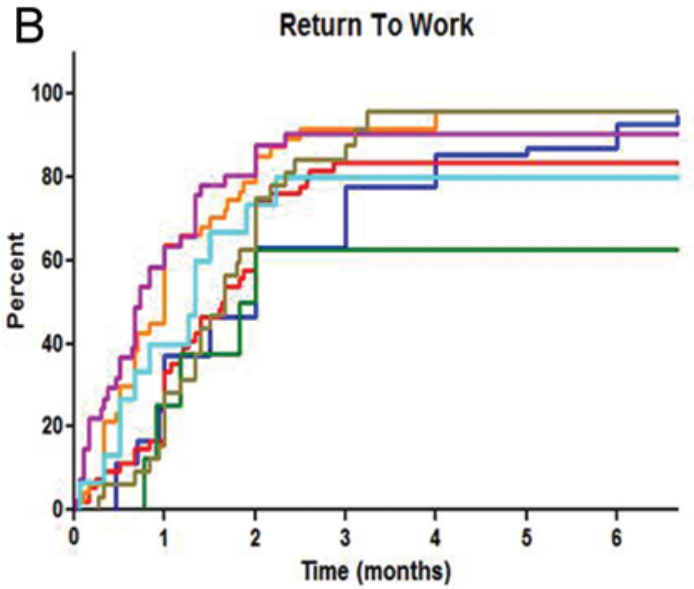

\section{- Lumbar Fusion}

- Lumbar Fusion

$\perp$ ACDF

- Deformity

- Revision ACDF

\section{Disability (ODI/NDI)}

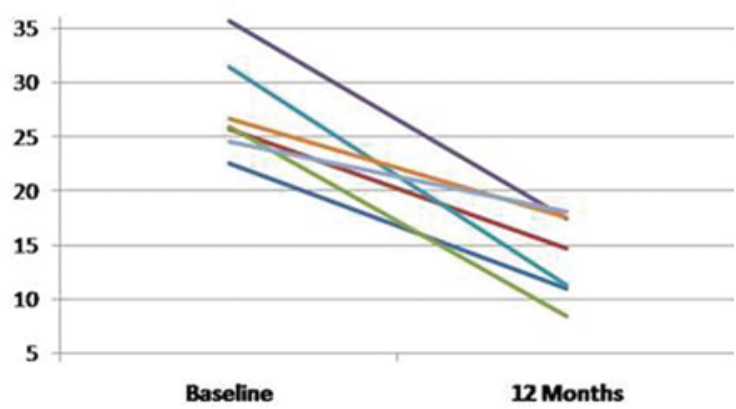

EQ-5D

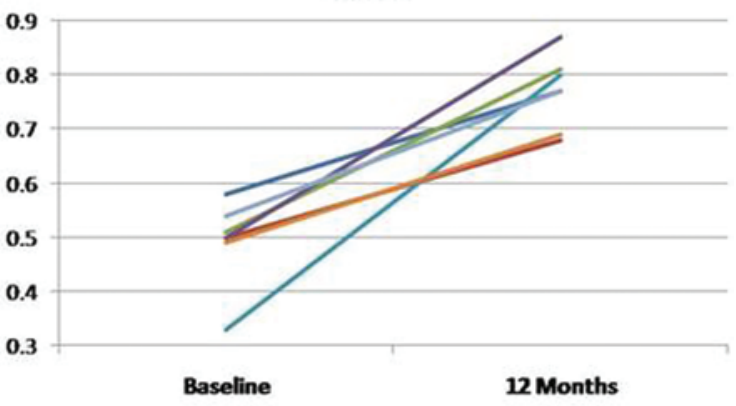

- Lumbar Discectomy

- Revision Lumbar Fusion

— Lumbar Laminectomy

- Lumbar Discectomy

- Revision Lumbar Fusion

FiG. 3. A: Analysis of the aggregate VSC surgical patient population allows for accountability and transparency in the effectiveness of surgical care provided in our local marketplace. B: Return-to-work data can be useful in contracting spine services with health care payers or purchasers. ACDF = anterior cervical discectomy and fusion.

Ultimately, registry participation is designed to assess surgical quality measures (length of stay, blood loss, operative time, perioperative morbidity, readmission, and reoperation), occupational measures (return to work and work capacity), and outcome measures (pain, disability, depression, and mental and physical QOL) for all surgical care. One year after launch of the registry, a subset of patients who were surgical candidates but chose to undergo medical management were enrolled in the registry. This subset included patients with lumbar disc herniation, lum- bar stenosis, or lumbar spondylolisthesis. This process has not yet been expanded to medically managed patients with other spine diagnoses. This strategy creates the opportunity to perform comparative effectiveness research addressing surgical and nonsurgical strategies in spine care using registry data.

\section{Medical Resource Utilization and Cost Estimates}

To estimate direct health care costs, patient-reported resource utilization during the follow-up time period is 
Outcome measurement in neurosurgery practice

TABLE 3: Quality, cost, and value of care for 7 commonly performed spinal treatments performed at a single institution in order of decreasing value*

\begin{tabular}{|c|c|c|c|c|c|c|}
\hline Procedure & $\begin{array}{c}\text { Cost } / 1-Y r \\
\text { QALY Gained } †\end{array}$ & $\begin{array}{l}\text { 1-Yr Direct } \\
\text { Health Care } \\
\text { Cost }\end{array}$ & $\begin{array}{c}\text { 1-Yr Indirect } \\
\text { Health Care } \\
\text { Cost }\end{array}$ & $\begin{array}{l}\text { Surgical } \\
\text { Morbidity }\end{array}$ & $\begin{array}{c}\text { NASS Satisfaction } \\
\text { Index }\end{array}$ & $\begin{array}{l}\text { Mean Return } \\
\text { to Work (wks) }\end{array}$ \\
\hline lumbar laminectomy for lumbar stenosis & $\$ 33,700$ & $\$ 14,264$ & $\$ 10,452$ & $5.6 \%$ & $73 \%$ & 10 \\
\hline ACDF for cervical radiculopathy & $\$ 42,320$ & $\$ 23,444$ & $\$ 6,322$ & $4 \%$ & $88 \%$ & 4 \\
\hline lumbar laminectomy \& fusion for spondylolisthesis & $\$ 42,854$ & $\$ 25,251$ & $\$ 11,584$ & $4.4 \%$ & $76 \%$ & 8.0 \\
\hline revision ACDF for adjacent-segment disease & $\$ 58,396$ & $\$ 25,391$ & $\$ 7,225$ & $7.5 \%$ & $75 \%$ & 5 \\
\hline revision lumbar fusion for recurrent stenosis & $\$ 58,846$ & $\$ 30,808$ & $\$ 12,879$ & $15 \%$ & $65 \%$ & 16.0 \\
\hline revision lumbar fusion for pseudarthrosis & $\$ 59,945$ & $\$ 28,751$ & $\$ 18,623$ & $12 \%$ & $53 \%$ & 20.0 \\
\hline revision lumbar fusion for adjacent-segment disease & $\$ 62,955$ & $\$ 28,239$ & $\$ 19,607$ & $2 \%$ & $77 \%$ & 8.0 \\
\hline medical management for lumbar disc herniation & $\$ 87,327$ & $\$ 8,427$ & $\$ 384$ & NA & $28 \%$ & NA \\
\hline medical management for lumbar stenosis & $\$ 95,500$ & $\$ 8,992$ & $\$ 358$ & NA & $30 \%$ & NA \\
\hline medical management for lumbar spondylolisthesis & $\$ 146,033$ & $\$ 9,191$ & $\$ 351$ & NA & $23 \%$ & NA \\
\hline
\end{tabular}

* Having effectiveness data (1-yr QALY gain) allows cost to be placed in the context of value. Value = effectiveness/cost (cost to gain a QALY [EQ-5D with US valuation]). Abbreviations: ACDF = anterior cervical discectomy and fusion; NA = not applicable.

collected and includes outpatient visits (surgeons, chiropractors, other physicians, physical therapists, acupuncturists, or other health care providers), spine-related diagnostic tests (radiography, CT scanning, MRI, and electromyography), injections, devices (for example, braces, canes, walkers, and shoe inserts), emergency room visits, and rehabilitation or nursing home days. Participants are asked in detail about their use of all medications, including but not limited to nonsteroidal antiinflammatory drugs and COX2 inhibitors, oral steroids, narcotics, muscle relaxants, and antidepressants.

To estimate the direct medical cost at each time point, self-reported instances of medical resource use are multiplied by unit costs for each cost component. Unit

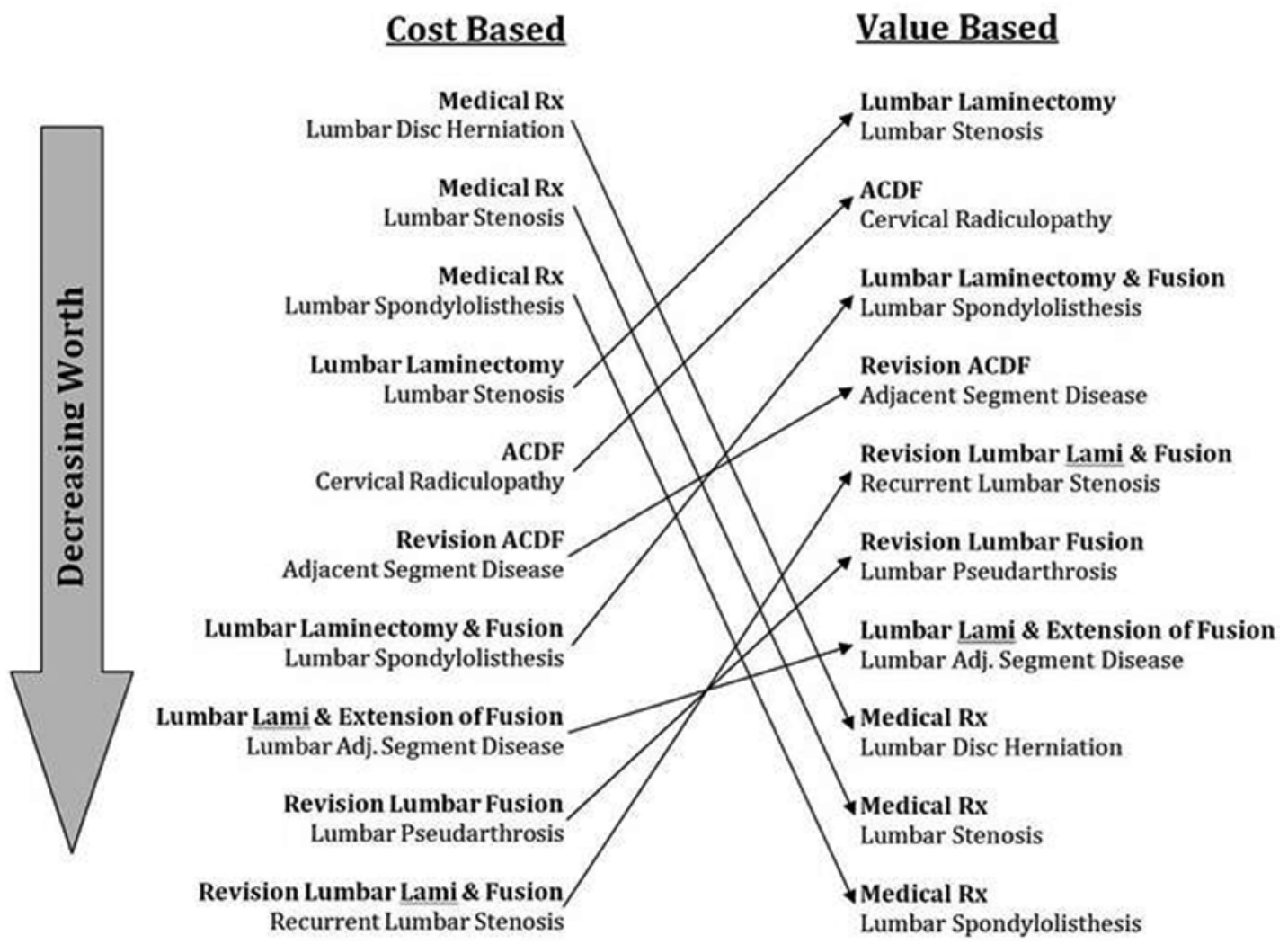

FIG. 4. Relative ranking of spine care procedures by 1-year cost alone and reranked by 1-year value (cost to gain a QALY (EQ$5 \mathrm{D}$ with US valuation). Value (effect per cost) versus cost alone assessment markedly influenced the rank of measured worth of various treatment options. Adj. = adjacent; Lami = laminectomy. 
costs for office visits, hospitalizations, diagnostic tests, and procedures are based on current Medicare national allowable payment amounts. Medication prices are based on the average wholesale price of the individual drugs obtained from First Data Bank's National Drug Data File Plus. Surgery costs depend on whether intraoperative complications occur, which determines the DRG. The current Medicare mean total DRG price is used to reflect hospital-related surgery costs. Surgeon costs are based on CPT codes submitted and current Medicare allowable amounts using the resource-based relative value scale. The DRG and CPT codes submitted for index surgery and any postoperative readmission are used to estimate direct cost of surgery and are added to all resource costs via macro-costing approach.

At each follow-up, productivity losses due to spinerelated problems (missed workdays for those employed outside of the home) are recorded. Costs are estimated using the standard human capital approach by multiplying the change in hours worked by the gross-of-tax wage rate.

\section{Examples of Practice Data Use}

\section{Feasibility of Measurement}

To ensure that a registry's observational data are representative of the overall practice, the number of patients actually captured and measured within a registry must be assessed. Randomized or representative sampling techniques, or alternatively total care sampling, should be attempted to avoid selection bias and to generate a representative cohort. In addition, the follow-up rate for 3 - and 12-month data collection should be greater than $80 \%$ to ensure that results are not skewed by varying tendencies among patients with different clinical characteristics to participate in data collection. At VSC, with a denominator representing the total volume of patients receiving surgical spine care, the registry enrollment rate is auto-calculated for monthly real-time reporting (Fig. 2). Ninety-two percent of patients undergoing elective spine surgery at the VSC participated in baseline outcome questionnaires and were captured in the Web-based registry. On average, $84 \%$ of patients complete outcome questionnaires 3 months and $81 \%$ complete them 12 months after spine surgery (Fig. 2). These proportions, reflecting the representativeness of analyzed data, are provided as part of all analyses and reports of patients, treatments, or subgroups.

\section{Demonstrating Effectiveness and Value of Care}

Analysis of the VSC surgical patient population allows for accountability and transparency in the effectiveness of surgical care provided in the VSC's local marketplace (Fig. 3A). The VSC has begun novel contracting strategies with second opinion programs and preferred provider status with self-insured employers and smaller health plans. Evidence regarding effectiveness of care, and, in particular, return to work (Fig. 3B) has been useful in contracting spine services with third-party payers. Furthermore, health care purchasers, employers, and state-run workers' compensation plans have expressed interest in gaining access to the VSC return-to-work reg- istry data through novel partnership programs. Having valid evidence regarding patient-centered effectiveness of care using outcome measurement has allowed the VSC to uniquely demonstrate the value of spine care in its local marketplace.

Obtaining utility (1-year QALY via EQ-5D) data for all surgical spine care has allowed the VSC to assess the relative value of its various spine treatments. One-year cost of care (payer's perspective) can then be placed in the context of effectiveness. The VSC registry approach to value definition has been to define an absolute value measure for a treatment: the cost required to obtain a full QALY gain. This is much different from an ICER (incremental cost-effectiveness ratio), where the difference in cost between two procedures is divided by their difference in utility. The incremental cost-effectiveness ratio assumes that the comparison treatment is either costeffective or is recognized as the gold standard for care, and also assumes a willingness-to-pay threshold. Rather, the VSC registry generates an absolute measure of 1-year cost of the procedure divided by the QALY gained from that procedure in our hands. Direct cost may be obtained from the accounting office or estimated from submitted CPT and DRG codes and resources used, multiplied according to the relevant Medicare fee schedule. Similar to comparing fuel efficiency in miles per gallon when purchasing an automobile, the VSC registry calculates how much a QALY costs with each treatment offered (Table $3)$. The emerging science of value analysis in real-world practice offers substantial benefit to spine care stakeholders. For patients with surgically relevant, structural spine pathology at the VSC, 1-year direct and indirect costs are significantly lower for medical than for surgical management (Table 3). However, in the context of value delivered, surgery is far superior to medical care in delivering effectiveness per increment of increased cost (for example, for

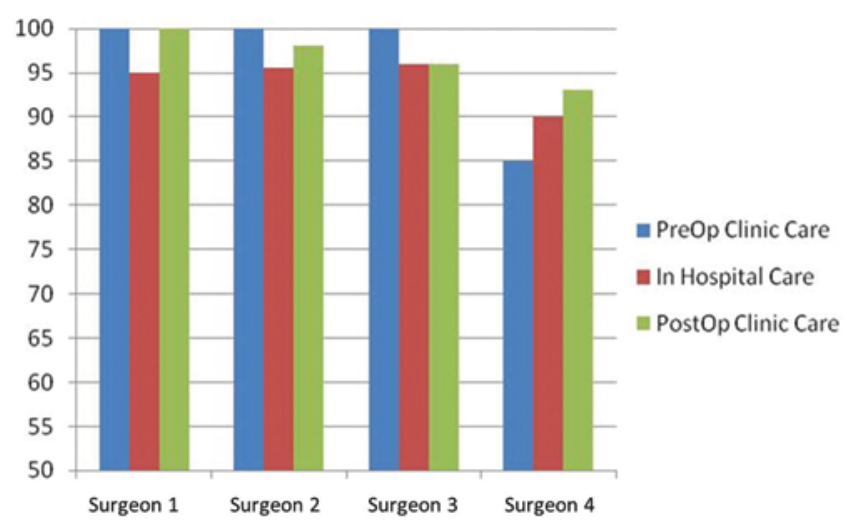

FIG. 5. Practice-based learning analysis allows comparison of patient satisfaction with outpatient clinic and inpatient hospital care across different surgical providers in the VSC. Total case measurement with the VSC registry is more trusted than hospital-wide satisfaction measures that sample only $5 \%$ of patient visits, most of which are not surgical and do not involve long-term care. The following example provides targeted improvement for a provider and his inpatient and outpatient staff. The patients are asked to rate their satisfaction with the preoperative clinic care, inhospital care, and postoperative care they received on a 5-point Likert scale (very satisfied, satisfied, neither satisfied nor dissatisfied, dissatisfied, and very dissatisfied). 
Outcome measurement in neurosurgery practice
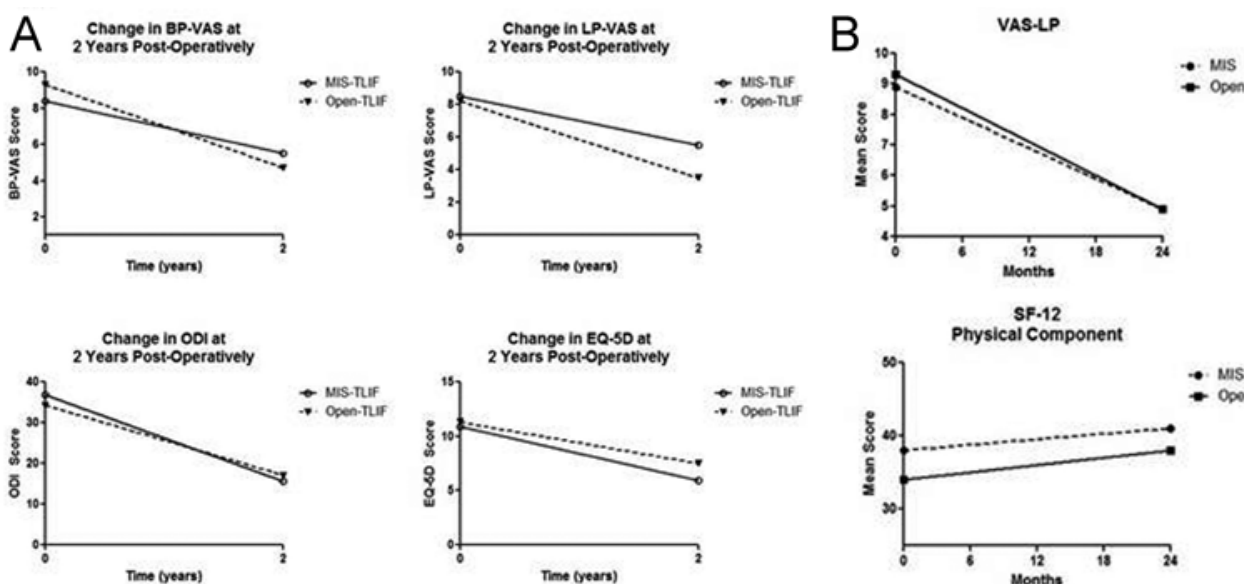

Post-Operative Time to No Narcotic Use
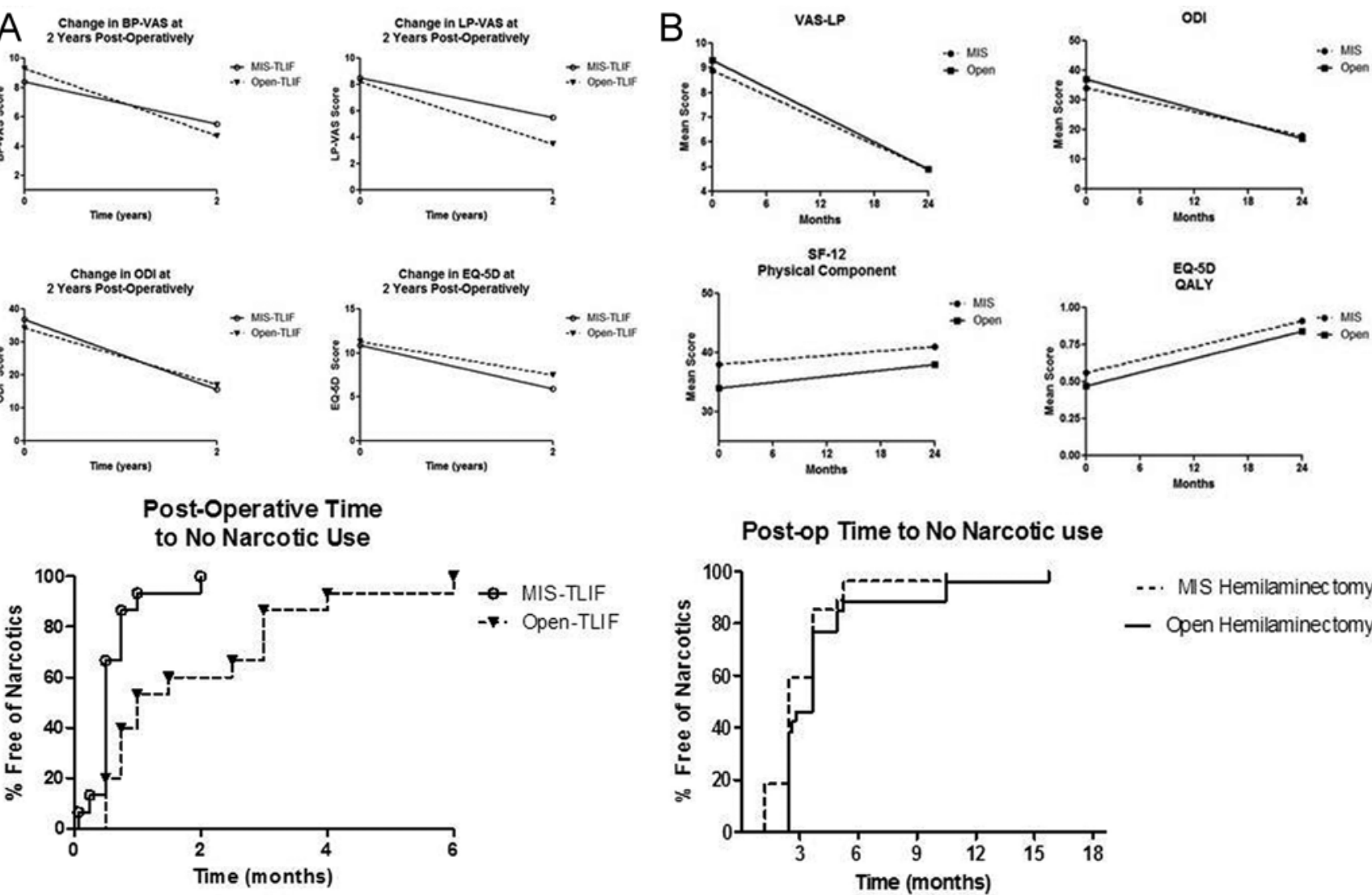

Post-op Time to No Narcotic use

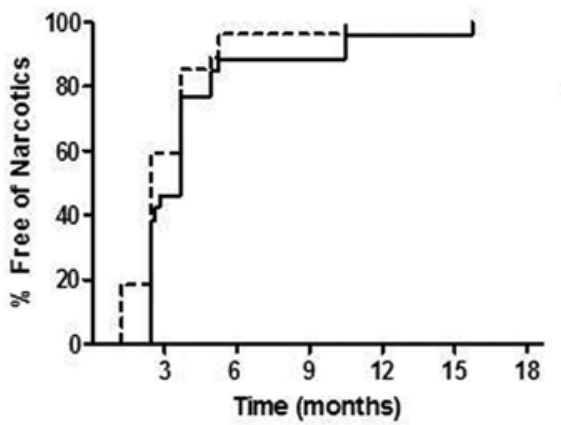

-.. MS Hemilaminec tomy

- Open Hemilaminectomy

Time to Return to Work

Post-Operatively
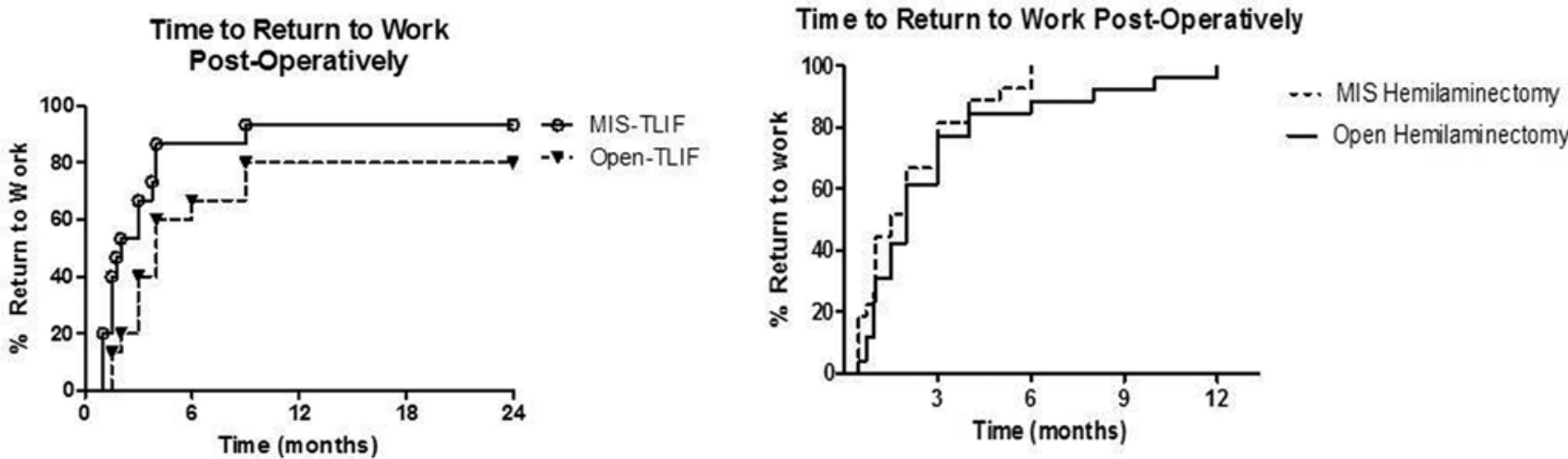

FIG. 6. Practice-based learning example of an analysis of whether the increasing adoption of minimally invasive tubular access at the VSC has improved care for transforaminal lumbar interbody fusion (TLIF) (A) and multilevel lumbar laminectomy for stenosis (B). For minimally invasive surgery (MIS) versus open TLIF, long-term outcomes were equivalent; however, return-to-work status and cessation of narcotic use were significantly improved with MIS-TLIF (see the article by Adogwa et al.). For lumbar stenosis, however, MIS versus open laminectomy was not associated with any long-or short-term benefits but was associated with an increase in durotomy from $1 \%$ to $8 \%$ and nerve root injury from $0 \%$ to $3 \%$. Care has shifted away from tubular access for laminectomy but has been maintained for TLIF. BP = back pain; LP = leg pain.

lumbar stenosis, surgery is 2.5 times as costly, but 5 times as effective) (Fig. 4). For lumbar stenosis at the VSC, the mean 1-year cost of medical versus surgical management was much lower (\$9350 vs $\$ 24,716$ ). However, a $\$ 95,500$ investment in medical care is required to obtain a QALY gain while only a $\$ 33,700$ investment in surgical care was required to obtain a QALY gain.

\section{Practice-Based Learning and Quality Improvement}

Access to outcome and safety data at the VSC practice has allowed for internal critical evaluation and practicebased learning. Systematic analysis of quality in practice has replaced the use of unreliable anecdotal recall without valid input from the patient's perspective. For example, identification of practitioners who are outliers for patient satisfaction data has allowed for targeted provider and clinic staff improvement (Fig. 5). Quality in practice data have also been used in determining whether increasing utilization of minimally invasive access techniques was improving care (Fig. 6); these same data have further been 
A

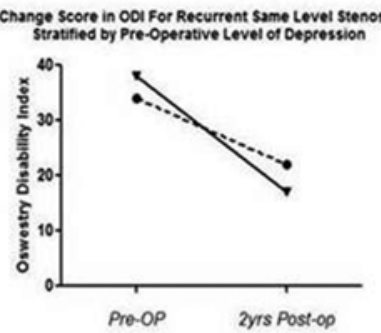

Change Score in OOI For Prevdarthrosis
Stratified by Pre- - p perative Level of Oepress

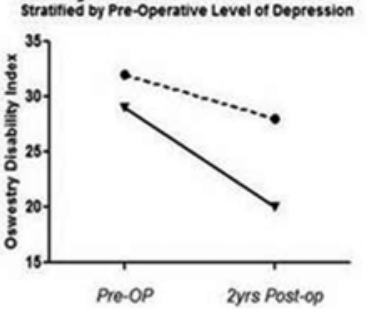

Change Score in OOI For Adjacent Segment Disease

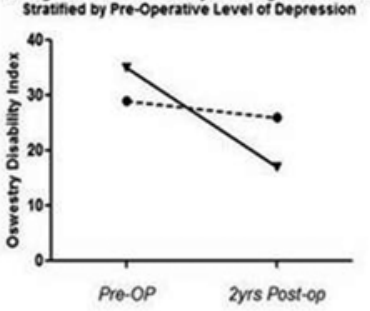

- Most Depressed PreOp (ZUNG)

- Least Depressed PreOp (ZUNG)
B

\section{Change in Patient Satisfaction with Increasing Pre-op Depression}

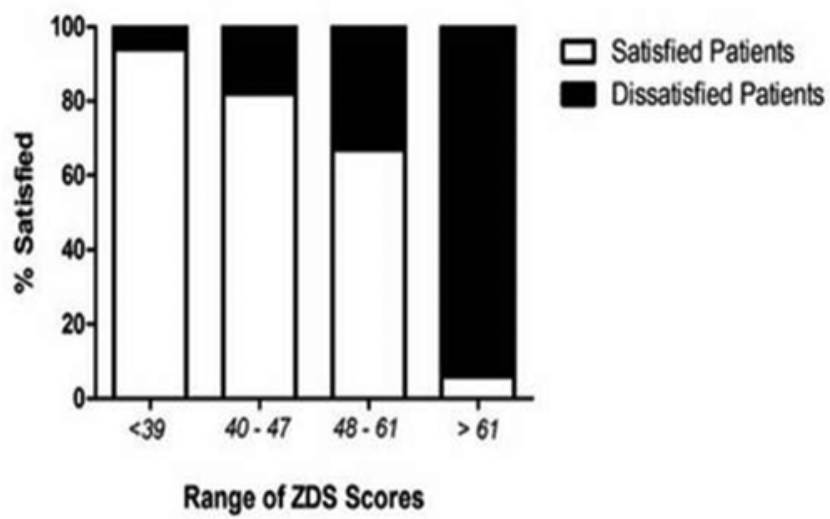

D

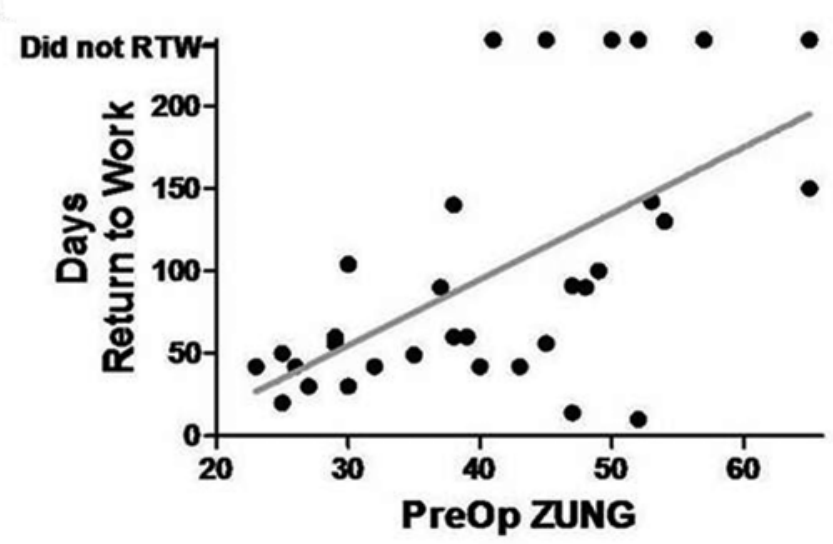

FIG. 7. Practice-based learning example of identifying patient subgroups least likely to respond to surgical spine care at the VSC. Increasing preoperative Zung Self-Rating Depression Scale (ZDS) correlated significantly with decreased surgical effectiveness (A), patient dissatisfaction with outcome (B), and attenuated return to work (RTW) (C). Example providing the identification of a patient subgroup (highly depressed, Zung Scale score $>60$ ) that may be best served with continued medical management (D). Shifting care away from this patient subgroup will decrease the overall waste and improve efficiency and value of care provided.

used to identify patient subgroups for whom VSC surgical care was least effective (Fig. 7) and to determine whether recently added surgical adjuncts were improving surgical quality (Fig. 8). In each of these scenarios, practice-based analysis demonstrating both favorable and unfavorable outcome resulted in shifts in future care delivery and practicebased learning.

\section{Conclusions}

Patient outcome measurement in health care delivery lies at the heart of patient-centered evidence of effectiveness, quality, and value of care. Whether in randomized trials, real-world comparative effectiveness research, policy and value-based purchasing, quality improvement, or practice-based learning, utilizing validated patient-reported outcome instruments is being encouraged by most evidence-driven health care stakeholders. Incorporating comprehensive patient assessment (pain, disability, QOL, and return to work) into standard of care practice empowers the provider and the hospital system to improve their quality and value of care through a patient-centered and practice-based learning approach. Registry efforts such as the $N^{2}$ QOD (National Neurosurgery Quality and Outcomes Database) are emerging that will allow practice groups of all types to engage in, and benefit from, this emerging culture of outcome data collection.

\section{Disclosure}

Drs. Selden and Asher are members of the board of directors of NeuroPoint Alliance. Dr. Asher is a consultant for Medtronic and Stryker Corp. and owns stock in Hyperbranch Medical Technologies.

Author contributions to the study and manuscript preparation include the following. Conception and design: McGirt, Speroff, Godil, Cheng, Asher. Acquisition of data: Godil. Analysis and interpretation of data: McGirt, Speroff, Godil, Selden, Asher. Drafting the article: all authors. Critically revising the article: McGirt, 


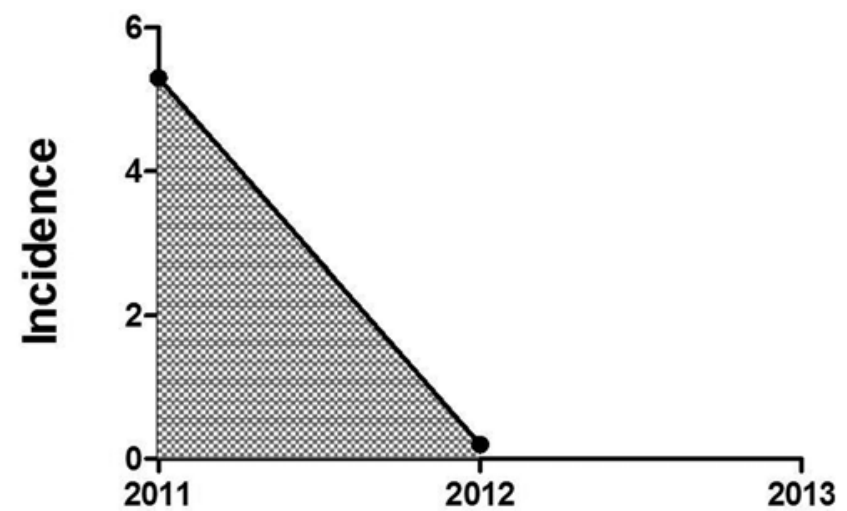

FIG. 8. A single-provider example of practice-based learning to determine whether the introduction of an intraoperative adjuvant therapy into practice improves quality of care. On January 1, 2012, a VSC surgeon began applying $2 \mathrm{~g}$ of vancomycin powder topically to all posterior spinal wounds for elective degenerative spine surgeries. A critical analysis of his practice 1 year after initiation of this adjuvant care demonstrated that the 2011 (prevancomycin) and 2012 (postvancomycin) surgery cohorts were similar in all regards. However, a significant reduction in surgical site infection was observed after initiating this adjuvant therapy as his standard of care $(5.3 \%$ vs $0 \%, p<0.01$; Fisher exact test). If systematic practice analysis had failed to demonstrate value, this practice would have stopped; however, evidence supporting quality improvement justifies its further use among all providers. Continued practice-based analysis in $\mathbf{2 0 1 3}$ will help confirm the effectiveness of this evolution in practice.

Speroff, Cheng, Selden, Asher. Reviewed submitted version of manuscript: McGirt. Approved the final version of the manuscript on behalf of all authors: McGirt.

\section{References}

1. Acquadro C, Berzon R, Dubois D, Leidy NK, Marquis P, Revicki D, et al: Incorporating the patient's perspective into drug development and communication: an ad hoc task force report of the Patient-Reported Outcomes (PRO) Harmonization Group meeting at the Food and Drug Administration, February 16, 2001. Value Health 6:522-531, 2003

2. Adogwa O, Parker SL, Bydon A, Cheng J, McGirt MJ: Comparative effectiveness of minimally invasive versus open transforaminal lumbar interbody fusion: 2-year assessment of narcotic use, return to work, disability, and quality of life. J Spinal Disord Tech 24:479-484, 2011

3. Amick BC III, Lerner D, Rogers WH, Rooney T, Katz JN: A review of health-related work outcome measures and their uses, and recommended measures. Spine (Phila Pa 1976) 25: 3152-3160, 2000

4. Andres E, Temme M, Raderschatt B, Szecsenyi J, Sandholzer $\mathrm{H}$, Kochen MM: COOP-WONCA charts: a suitable functional status screening instrument in acute low back pain? $\mathbf{B r} \mathbf{J}$ Gen Pract 45:661-664, 1995

5. Andresen EM, Fouts BS, Romeis JC, Brownson CA: Performance of health-related quality-of-life instruments in a spinal cord injured population. Arch Phys Med Rehabil 80:877884, 1999

6. Bergner M, Bobbitt RA, Carter WB, Gilson BS: The Sickness Impact Profile: development and final revision of a health status measure. Med Care 19:787-805, 1981

7. Beurskens AJ, de Vet HC, Köke AJ: Responsiveness of functional status in low back pain: a comparison of different instruments. Pain 65:71-76, 1996

8. Bombardier C: Outcome assessments in the evaluation of treatment of spinal disorders: summary and general recommendations. Spine (Phila Pa 1976) 25:3100-3103, 2000

9. Brazier J, Usherwood T, Harper R, Thomas K: Deriving a preference-based single index from the UK SF-36 Health Survey. J Clin Epidemiol 51:1115-1128, 1998

10. Brazier JE, Walters SJ, Nicholl JP, Kohler B: Using the SF-36 and Euroqol on an elderly population. Qual Life Res 5:195204, 1996

11. Brooks R: EuroQol: the current state of play. Health Policy 37:53-72, 1996

12. Chapman JR, Norvell DC, Hermsmeyer JT, Bransford RJ, DeVine J, McGirt MJ, et al: Evaluating common outcomes for measuring treatment success for chronic low back pain. Spine (Phila Pa 1976) 36 (21 Suppl):S54-S68, 2011

13. DeVine J, Norvell DC, Ecker E, Fourney DR, Vaccaro A, Wang J, et al: Evaluating the correlation and responsiveness of patient-reported pain with function and quality-of-life outcomes after spine surgery. Spine (Phila Pa 1976) 36 (21 Suppl):S69-S74, 2011

14. Edelman D, Williams GR, Rothman M, Samsa GP: A comparison of three health status measures in primary care outpatients. J Gen Intern Med 14:759-762, 1999

15. Essink-Bot ML, Krabbe PF, Bonsel GJ, Aaronson NK: An empirical comparison of four generic health status measures. The Nottingham Health Profile, the Medical Outcomes Study 36item Short-Form Health Survey, the COOP/WONCA charts, and the EuroQol instrument. Med Care 35:522-537, 1997

16. EuroQol Group: EuroQol-a new facility for the measurement of health-related quality of life. Health Policy 16:199-208, 1990

17. Fairbank JC, Couper J, Davies JB, O’Brien JP: The Oswestry low back pain disability questionnaire. Physiotherapy 66: 271-273, 1980

18. Fritz JM, Piva SR: Physical impairment index: reliability, validity, and responsiveness in patients with acute low back pain. Spine (Phila Pa 1976) 28:1189-1194, 2003

19. Frost H, Lamb SE, Stewart-Brown S: Responsiveness of a patient specific outcome measure compared with the Oswestry Disability Index v2.1 and Roland and Morris Disability Questionnaire for patients with subacute and chronic low back pain. Spine (Phila Pa 1976) 33:2450-2458, 2008

20. Greenough CG, Fraser RD: Assessment of outcome in patients with low-back pain. Spine (Phila Pa 1976) 17:36-41, 1992

21. Grönblad M, Hupli M, Wennerstrand P, Järvinen E, Lukinmaa A, Kouri JP, et al: Intercorrelation and test-retest reliability of the Pain Disability Index (PDI) and the Oswestry Disability Questionnaire (ODQ) and their correlation with pain intensity in low back pain patients. Clin J Pain 9:189-195, 1993

22. Grotle M, Brox JI, Vollestad NK: Concurrent comparison of responsiveness in pain and functional status measurements used for patients with low back pain. Spine (Phila Pa 1976) 29:E492-E501, 2004

23. Harris PA, Taylor R, Thielke R, Payne J, Gonzalez N, Conde JG: Research electronic data capture (REDCap) - a metadata-driven methodology and workflow process for providing translational research informatics support. J Biomed Inform 42:377-381, 2009

24. Hunt SM, McEwen J, McKenna SP: Measuring health status: a new tool for clinicians and epidemiologists. J R Coll Gen Pract 35:185-188, 1985

25. Kopec JA: Measuring functional outcomes in persons with back pain: a review of back-specific questionnaires. Spine (Phila Pa 1976) 25:3110-3114, 2000

26. Kopec JA, Esdaile JM, Abrahamowicz M, Abenhaim L, Wood-Dauphinee S, Lamping DL, et al: The Quebec Back Pain Disability Scale: conceptualization and development. J Clin Epidemiol 49:151-161, 1996

27. Kopec JA, Esdaile JM, Abrahamowicz M, Abenhaim L, Wood-Dauphinee S, Lamping DL, et al: The Quebec Back 


\section{J. McGirt et al.}

Pain Disability Scale. Measurement properties. Spine (Phila Pa 1976) 20:341-352, 1995

28. Lauridsen HH, Hartvigsen J, Manniche C, Korsholm L, Grunnet-Nilsson N: Responsiveness and minimal clinically important difference for pain and disability instruments in low back pain patients. BMC Musculoskelet Disord 7:82, 2006

29. Lohr KN, Schroeder SA: A strategy for quality assurance in Medicare. N Engl J Med 322:707-712, 1990

30. Lurie J: A review of generic health status measures in patients with low back pain. Spine (Phila Pa 1976) 25:3125-3129, 2000

31. Maughan EF, Lewis JS: Outcome measures in chronic low back pain. Eur Spine J 19:1484-1494, 2010

32. McHorney CA, Tarlov AR: Individual-patient monitoring in clinical practice: are available health status surveys adequate? Qual Life Res 4:293-307, 1995

33. Németh G: Health related quality of life outcome instruments. Eur Spine J 15 (Suppl 1):S44-S51, 2006

34. Parker SL, Adogwa O, Paul AR, Anderson WN, Aaronson $\mathrm{O}$, Cheng JS, et al: Utility of minimum clinically important difference in assessing pain, disability, and health state after transforaminal lumbar interbody fusion for degenerative lumbar spondylolisthesis. Clinical article. J Neurosurg Spine 14:598-604, 2011

35. Parker SL, Mendenhall SK, Shau D, Adogwa O, Cheng JS, Anderson WN, et al: Determination of minimum clinically important difference in pain, disability, and quality of life after extension of fusion for adjacent-segment disease. Clinical article. J Neurosurg Spine 16:61-67, 2012

36. Parker SL, Mendenhall SK, Shau DN, Adogwa O, Anderson WN, Devin CJ, et al: Minimum clinically important difference in pain, disability, and quality of life after neural decompression and fusion for same-level recurrent lumbar stenosis: understanding clinical versus statistical significance. Clinical article. J Neurosurg Spine 16:471-478, 2012
37. Parkerson GR Jr, Broadhead WE, Tse CK: The Duke Health Profile. A 17-item measure of health and dysfunction. Med Care 28:1056-1072, 1990

38. Roland M, Morris R: A study of the natural history of back pain. Part I: development of a reliable and sensitive measure of disability in low-back pain. Spine (Phila Pa 1976) 8:141-144, 1983

39. Shaw JW, Johnson JA, Coons SJ: US valuation of the EQ-5D health states: development and testing of the D1 valuation model. Med Care 43:203-220, 2005

40. Suzukamo Y, Fukuhara S, Green J, Kosinski M, Gandek B, Ware JE: Validation testing of a three-component model of Short Form-36 scores. J Clin Epidemiol 64:301-308, 2011

41. Vernon H: The Neck Disability Index: state-of-the-art, 19912008. J Manipulative Physiol Ther 31:491-502, 2008

42. Waddell G, Main CJ: Assessment of severity in low-back disorders. Spine (Phila Pa 1976) 9:204-208, 1984

43. Ware J Jr, Kosinski M, Keller SD: A 12-Item Short-Form Health Survey: construction of scales and preliminary tests of reliability and validity. Med Care 34:220-233, 1996

44. Ware JE Jr, Kosinski M, Gandek B, Aaronson NK, Apolone G, Bech P, et al: The factor structure of the SF-36 Health Survey in 10 countries: results from the IQOLA Project. International Quality of Life Assessment. J Clin Epidemiol 51:1159-1165, 1998

Manuscript submitted September 10, 2012.

Accepted October 1, 2012.

Please include this information when citing this paper: DOI: 10.3171/2012.10.FOCUS12298.

Address correspondence to: Matthew J. McGirt, M.D., 4347 Village at Vanderbilt, Nashville, Tennessee 37232-8618. email: matt. mcgirt@vanderbilt.edu. 